\title{
Chapter 27 \\ Using Quality Assurance Frameworks \\ to Support an Institutional Culture \\ of Academic Integrity at Canadian \\ Universities
}

\section{Emma J. Thacker $[$ and Amanda McKenzie $[$ ]}

\begin{abstract}
In Canada, there is a national academic quality assurance framework - the Canadian Degree Qualifications Framework (CDQF) that guides quality assurance standards within universities across the provinces and territories. These standards exist to support the quality and consistency of postsecondary academic programming in Canada, and provide mechanisms for quality enhancement. The CDQF is supported by further quality assurance mechanisms at the provincial level. While the CDQF includes the notion of academic integrity as a learning outcome requirement, the implementation and review of this quality indicator across the sector is nebulous. The ongoing support for a culture of academic integrity requires a holistic approach, which includes the alignment of various policies and processes. It also involves the inclusion of academic integrity best practices into quality assurance processes, such as curriculum development and program review. In this chapter we discuss several quality assurance tools used in Canadian universities, with a focus on Ontario institutions, and discuss opportunities to leverage them to support academic integrity. The CDQF and provincial/territorial quality assurance frameworks should be better utilized for a holistic response to academic misconduct, to strengthen teaching and learning, and develop a culture of integrity in higher education. Opportunities within cyclical program review, curriculum mapping and educational development are discussed to highlight opportunities for academic integrity specialists, quality assurance staff, faculty, and policy makers to raise academic integrity awareness and weave best practices across an institution. Implications for the community college sector are also included. Recommendations can be applied to postsecondary institutions across Canada and integrated with quality assurance practices promoted by the Quality Assurance Agency (QAA) and others academic integrity advocates around the world.
\end{abstract}

\footnotetext{
E. J. Thacker $(\varangle)$

University of Toronto Scarborough, 1265 Military Trail, Toronto, ON M1C1A4, Canada e-mail: em.thacker@utoronto.ca
}

\author{
A. McKenzie \\ University of Waterloo, 200 University Ave. West, Waterloo, ON N2L 3G1, Canada \\ e-mail: amanda.mckenzie@uwaterloo.ca
}

S. E. Eaton and J. Christensen Hughes (eds.), Academic Integrity in Canada,

Ethics and Integrity in Educational Contexts 1 ,

https://doi.org/10.1007/978-3-030-83255-1_27 
Keywords Academic integrity $\cdot$ Canada $\cdot$ Curriculum mapping $\cdot$ Educational development $\cdot$ Learning outcomes $\cdot$ Program review $\cdot$ Quality assurance $\cdot$ Quality enhancement $\cdot$ University

Quality assurance frameworks require postsecondary institutions to engage in a variety of methods and approaches to ensure high quality academic programming. These frameworks and processes have been created in countries all over the globe (INQAAHE, 2020), and are viewed as critical to support the accountability of publicly assisted institutions. High quality programs require support and resources from many departments and areas of expertise in an institution. Staff and faculty across the institution work together to ensure that students receive educational experiences that not only positively impact their lives, but support the economy, local communities, and address global responsibilities. Quality educational experiences also uphold rigorous academic integrity to position graduates to move forward with high ethical standards in the next stage of their professional or academic lives. In this chapter we argue that quality assurance mechanisms can be used to promote and reinforce academic integrity, which results in long term positive impacts for students, higher educational institutions, and communities at large.

Academic integrity is critical to the education sector-without it credentials lack value and institutional reputation can be degraded. Academic misconduct also creates concern for the value of research itself and that research expertise is not trusted (Bretag, 2019a). Moreover, students may transition into employment without the skills and knowledge gained through rigorous academic programming and assessment. Students also risk their own reputations and credibility and may repeat academic misconduct (Curtis \& Clare, 2017) or engage in similar misconduct behaviours later in their careers (Guerrero-Dib et al., 2020). Issues of academic dishonesty are not new, having persisted at institutions much longer than formal policy has existed to respond to it (Bertram Gallant, 2008b). Evolving forms of academic misconduct such as contract cheating (Clarke \& Lancaster, 2007), also known as assignment outsourcing (Awdry, 2020), are exacerbated by socio-economic inequities, the commodification of education, and easy access to technology worldwide. This has required academic institutions to take a more active role in academic integrity education and implement preventative strategies. Some institutions are responding with the creation of dedicated academic integrity offices and committees, enhanced deterrence and detection initiatives, and robust policy revision. In Canada, academic integrity and quality assurance are not often regarded as interlinked processes and are typically located in separate departments, with little intersection. This chapter seeks to highlight how the overarching Canadian Degree Qualifications Framework (CDQF) allows for the two operations to overlap and work in concert to achieve their goals. Instead of having to build something completely new to help address academic integrity, we propose instead that institutions maximize and build upon pre-existing processes. In this chapter, we further offer recommendations to utilize the existing quality assurance framework as a mechanism to foster changes 
to the institutional academic integrity culture and reinforce academic quality and excellence.

\section{Canadian Quality Assurance}

In Canada, the oversight of higher education is decentralized (Weinrib \& Jones, 2014), with each province and territory having responsibility for the quality assurance of its university programs. This education structure was determined in 1867 and is written into Canada's Constitution Act (Robson, 2012). Although oversight for the quality assurance frameworks differ in universities across Canada, their quality assurance processes are relatively homogenous with similar foundational principles and many of the same broad processes. The Canadian government does not have a federal ministry or department of education like the United States (U.S. Department of Education, n.d.), nor does it have a national higher education quality assurance agency, such as the United Kingdom's independent body: Quality Assurance Agency for Higher Education (QAA, n.d.) or the Australian Government's Tertiary Education Quality and Standards Agency (TEQSA, 2020). That said, Universities Canada, a national university advocacy association, requires that all institutional members adhere to a set of criteria, and commit to, "[a] quality assurance policy that results in cyclical or continuous assessment of all of its academic programs and support services, and which includes the participation by those directly involved in delivery of the program or service, as well as by other institutional colleagues and external experts and stakeholders" (Universities Canada, n.d., para. 5).

Universities Canada endorses the CDQF in the Ministerial Statement on Quality Assurance of Degree Education in Canada (CMEC, 2007). This Ministerial statement reinforces a common, national standard and clarifies aspects of institutional autonomy. The CDQF lays out the degree categories (i.e., Bachelors, Master's, Doctoral), their typical length, minimum admission requirements and qualification standards. These standards, often referred to as 'degree level expectations' (DLEs), describe competencies and general learning outcomes, including an outcome to support academic integrity. The CDQF also discusses institutional standards for becoming a degree granting institution and refers to 'Ethical Conduct' and 'Academic Freedom \& Integrity' as a standard (CMEC, 2007, p. 12).

The overall CDQF is evident within each institutions degree criteria, however there are differences in how this is reflected across the provinces. In Ontario, for example, the Canadian Framework DLEs are for the most part reproduced in two quality assurance documents: 1) the Ontario Council of Academic Vice-Presidents (OCAV) Undergraduate and Graduate Degree Level Expectations (OUCQA, n.d.); and 2) the Ontario Qualifications Framework (OQF) (MCU, 2018). There is one notable exception in the OQF. Academic integrity is included as a learning outcome for all Bachelor, Master's, and Doctoral programs (see Tables 27.1 and 27.2), whereas, the CDQF only explicitly refers to academic integrity at the Bachelor's level, although it is implied that the standards are cumulative, "and each degree level presupposes the 
Table 27.1 OCAV's Undergraduate Degree Level Expectations (DLE)

\begin{tabular}{l|l|l}
\hline Degree Level Expectation & $\begin{array}{l}\text { Baccalaureate/ } \\
\text { Bachelor's Degree }\end{array}$ & $\begin{array}{l}\text { Baccalaureate/ } \\
\text { Bachelor's Degree (Honours) }\end{array}$ \\
\hline Autonomy and Professional & $\begin{array}{l}\text { "behaviour consistent with } \\
\text { academic integrity and social } \\
\text { Capacity }\end{array}$ & $\begin{array}{l}\text { "behaviour consistent with } \\
\text { academic integrity and social } \\
\text { p.3) }\end{array}$ \\
\hline
\end{tabular}

Note Table italics added. Table adapted from Ontario Universities Council on Quality Assurance (OUCQA, n.d.)

Table 27.2 OCAV's Graduate Degree Level Expectations (DLE)

\begin{tabular}{l|l|l}
\hline Degree Level Expectation & Master's Degree & Doctoral Degree \\
\hline Autonomy and Professional & "The ethical behaviour \\
consistent with academic & $\begin{array}{l}\text { integrity and the use of } \\
\text { appropriate guidelines and } \\
\text { procedures for responsible } \\
\text { conduct of research" } \\
\text { (OUCQA, n.d., p. 5) }\end{array}$ & $\begin{array}{l}\text { "The ethical behaviour } \\
\text { integrity and the use of } \\
\text { appropriate guidelines and } \\
\text { procedures for responsible } \\
\text { conduct of research" } \\
\text { (OUCQA, n.d., p. 5) }\end{array}$ \\
\hline
\end{tabular}

Note Table italics added. Table adapted from Ontario Universities Council on Quality Assurance (OUCQA, n.d.)

accomplishment of an earlier one" (CMEC, 2007, p. 3). Ontario is not alone in its use of a provincial framework; for example, the Province of Alberta provides a qualifications framework which notes academic integrity at the Bachelor's level (Alberta Government, 2018, p. 8). In British Columbia, the 'Degree Program Review Criteria and Guidelines' include academic integrity as a degree level standard at the Bachelor level (BCMAEST, 2017, p. 16). The Maritime Provinces also provide a qualifications framework, and while adapted from the CDQF, does not provide a specific learning outcome for academic integrity (MPHEC, n.d.). It is worth considering how the CDQF and the other provincial frameworks or guidelines could be enhanced to ensure that an academic integrity outcome is included and required for all credentials (e.g., Diploma, Certificate). This would support academic integrity initiatives and curriculum enhancement across all postsecondary programming, particularly within the College sector.

The Ontario College sector (with the exception of Bachelor degrees offered by Colleges) relies on vocational program learning outcomes and essential employability skills (EES) to demonstrate program quality. While the EESs include learning outcomes related to information management, demonstrating personal responsibility, and communication, there is no direct reference to academic integrity (MCU, 2009a). Vocational program learning outcomes differ for each program, with no Ontario College Quality Assurance Service (OCQAS, 2020) requirement to include academic integrity at the program or course level. 
Most Canadian postsecondary programs follow a continuous improvement (Jacobsen et al., 2018; Temponi, 2005) quality assurance approach, although compliance, audit, and accreditation models also exist (Harvey, 2008). The continuous improvement approach, typically modeled with cyclical program review, includes self and peer evaluation, leading to a set of recommendations for ongoing program enhancement. A compliance model would be seen during new degree development, and involves an external regulatory body with the authority to appraise a proposed new program and determines if it, "meets or exceeds minimum expectations" (Harvey, 2008, p. 13). The Ontario College sector provides an example of an institutional audit process where there is a "review of each college's quality assurance mechanisms" (OCQAS, 2020, para. 1) however it is not, "accompanied by any threshold judgement" (Harvey, 2008, p. 13). The Ontario College institutional audit process includes an audit panel, site visit and self-study audit report (OCQAS, 2016). Lastly, quality assurance for most professional programs with regulated designations such as Professional Engineer (P.Eng) or Registered Nurse (R.N.), would fall under an accreditation model (UNESCO, 2007), and would thus work with external accreditation bodies such as Engineers Canada (Engineers Canada, n.d.); however, they must also comply with the internal quality assurance processes of their institution. This can create tension throughout the review process; however, the inclusion of an academic integrity outcome in the CDQF supports the importance of these outcomes at the provincial and institutional levels. Research suggests that national academic standards, while serving to provide expectations, consistency, and transparency, make a "modest contribution to assuring academic standards" (Dill \& Beerkins, 2013, p. 344). This suggests that while national frameworks are an essential foundation, local policy, procedure, and strategies must be utilized to enact real and lasting change.

Quality assurance frameworks have also been developed with an Indigenous perspective. The New Zealand Qualifications Authority for instance recognizes indigenous knowledge and education, and includes the 'Mātauranga Māori Evaluative Quality Assurance' approach (NZQA, n.d). In Ontario, Canada, the 'Indigenous Quality Assurance Standards in Ontario Colleges' framework, was developed by the Indigenous Knowledge Gifters' Council (IKGC, 2018). As of 2017, Indigenous Institutes in Ontario are included in the OQF. While Indigenous quality assurance approaches reflect an Indigenous context and vison, there are shared elements with the CDQF and the principles underlying academic integrity. The 'Indigenous Quality Assurance Standards in Ontario Colleges' framework notes a Seven Grandfathers Teaching, of "Gwekwaadziwin (Honesty)" (IKGC, 2018, p. 4). Another example is an academic integrity resource for Indigenous students entitled, "Seven Grandfathers in Academic Integrity" (Maracle, 2020) developed at the University of Toronto, First Nations House. Although the focus of this chapter is not Indigenous quality assurance or Indigenous perspectives on academic integrity (see Poitras Pratt \& Gladue, 2022), the congruence of quality assurance and academic integrity principles across the Canadian postsecondary landscape is nevertheless noteworthy, regardless of the institutional and cultural approach. The implementation of a strong quality assurance framework and development of holistic approaches to academic integrity in Canada 
must be developed in the context of decolonization and the Truth and Reconciliation Commission of Canada: Calls to Action (2015). The integration of quality assurance, academic integrity and Indigenous "cultural standards" (Northern College, 2017 , p. 5) are nicely reflected in the quality assurance policy at Ontario's Northern College (Northern College, 2017).

\section{Academic Integrity in Canada}

Academic institutions in Canada typically establish academic integrity or academic discipline policies, which outline academic expectations and provide a process for responding to academic misconduct, such as cheating or plagiarism (Stoesz et al., 2019). Over time, many institutions have moved away from the penalty focus of academic misconduct, to more pro-active, educative options (Christensen Hughes \& McCabe, 2006; Bertram Gallant, 2008a; Bretag, 2019b). Educative options typically include instructional workshops, videos, tutorials, and online modules (Griffith, 2013), aimed to reduce intentional and unintentional plagiarism. Some institutions require completion of academic integrity education modules as part of student orientation, or as a result of a misconduct sanction (Penaluna \& Ross, 2022).

Although other countries have quality assurance agencies that are actively engaged in academic integrity initiatives, such as the QAA's work on contract cheating (QAA, 2017; 2020), the Council for Higher Education Accreditation (CHEA, 2019), and TEQSA's Higher Education Integrity Unit (TEQSA, June 24, 2020), Canada does not have a national quality assurance body nor one that actively promotes academic integrity. The role of national quality assurance associations has been researched with regard to academic integrity and corruption (CHEA, 2015; Garwe, 2019; Glendinning, 2020), and although the resulting recommendations are valuable, without a national quality assurance agency in Canada, institutions must leverage alternative provincial and local strategies to support a culture of academic integrity. Canadian academic integrity practitioners and scholars are growing networks and these are bolstered through collective research and professional organizations (McKenzie et al., 2020; Stoesz et al., 2020). Several provinces in Canada also have organized associations or groups such as the Academic Integrity Council of Ontario (AICO, n.d.), the Manitoba Academic Integrity Network (MAIN, 2019), and the Alberta Council on Academic Integrity (ACAI, 2020). Many Canadian educational institutions are also members of the International Center for Academic Integrity (ICAI, 2020) as well as the ICAI Canadian Consortium, formed in 2014 (McKenzie, 2018). These organizations promote nation-wide networking, information sharing, research projects and innovative practices, including support for a holistic approach to nurture a culture of academic integrity.

Holistic approaches are promoted by many academic integrity scholars (Bertram Gallant, 2008a; Bretag, 2013; Morris \& Carroll, 2015; Macdonald \& Carroll, 2006), however institutions have been slow to adopt this approach. A holistic approach to academic integrity considers all stakeholders in an institution and works towards a 
shared understanding and responsibility for academic excellence to develop a culture of academic integrity. Although academic integrity policy, detection, and deterrence are critical, the holistic approach promoted by several academic integrity organizations in Canada moves away from a legalistic discourse (Sutherland-Smith, 2014), and a detection priority (QAA, 2020, p. 2), and leans more toward teaching and learning solutions.

Although this approach is promoted by several academic integrity organizations and scholars in Canada, there is still a great amount of work to be done to ensure that these approaches are supported by institutional leadership and administration. Developing a culture of integrity requires an institution to articulate their values into policy and practice, and reconsider euro-centric perspectives. The development of an institution-wide academic integrity strategy can be helpful to evaluate what academic integrity tools are available, what is working and what improvements can be made. Collaborative strategies require leadership, teamwork, authenticity, and a shared vision for onboarding new students, teachers, and staff into this institutional integrity culture. A culture of academic integrity also requires the weaving of academic integrity principles and processes into an institution's policy, teaching and learning practices. Each culture of academic integrity will look different in different institutions and must be grounded within an institution's values and promoted to all community stakeholders to flourish. Quality assurance policy, procedures, and continuous improvement activities can be a unifying mechanism to engage all stakeholders in the continual process of creating a culture of academic integrity and to raise the level of integrity across the board.

\section{Quality Assurance Tools to Leverage Academic Integrity}

\section{Cyclical Program Review}

Although each province, territory, and institution will differ slightly in process, cyclical program review is commonly understood to be the process to review academic programs for their strengths, challenges, and future direction (CMEC, 2007) leading to a set of recommendations and plans for improvement. Program review contains many elements, but common processes include a self-study or selfassessment, external review by disciplinary peer experts, a recommendations report with institutional response, and transparent reporting of the review outcomes. Selfstudies combine quantitative and qualitative data for analysis and assessment. Qualitative examples include student focus groups or individual interviews; whereas, quantitative data may include performance indicators such as time-to-completion and attrition rates. A program review involves critical thinking about program challenges and opportunities, and developing action plans for short- and long-term improvement. Herein, lies the opportunity to highlight and promote academic integrity. 
Many Canadian institutions, both college and university, have some flexibility over the content required in their program review 'self-study' report (Jacobsen et al., 2018; Liu, 2020; McKenzie, 2019; OUCQA, 2019). This flexibility allows institutions the chance to expand on specific enhancement goals and commitments such as Indigeneity, work-integrated learning, and academic integrity. To increase attention to academic integrity, a university could add questions to their self-study template such as, "what does your program currently do to enhance academic integrity?" or "what initiatives does your program plan to adopt in order to promote academic integrity?" (McKenzie, 2019). Inclusion of such questions in a self-study means that these questions must be revisited in subsequent program reviews, and there is therefore accountability for implementation of any improvement recommendations. It can also provide opportunities for programs to consider how to incorporate existing resources on campus such as the Library, Centre for Teaching and Learning (CTL), and Indigenous Centres for additional academic integrity support. Self-assessment is also a time to consider what academic integrity initiatives or supports are working well, and to ensure their continuity.

Self-study activities often include seeking student and alumni views. Students can provide valuable information to understand the existing culture of academic integrity within a program and make recommendations for academic integrity initiatives. Students can also be asked about how they were supported to learn about academic citation practices, their level of understanding about the academic integrity policy, their perception of academic misconduct in the program and the use of various academic integrity tools, such as text matching software (e.g., Turnitin) (Turnitin, 2020) or online proctoring services (e.g., Examity) (Examity, 2020), and opportunities to enhance student engagement in maintaining academic integrity. Program specific information can help to shore up pedagogical issues contributing to academic dishonesty, and curriculum related opportunities (e.g., course embedded library workshops related to research assignments or designing alternative assessments). Students can be engaged candidly to ask how they have navigated academic integrity throughout the program, and provide tangible tips to support assessment redesign, for example the inclusion of citation skills into assignment rubrics or iterative feedback (Barker \& Pinard, 2014) with assignments. Alumni might also offer insights into areas that have long standing issues with academic integrity such as key programs or courses that were known to be difficult and where students were tempted to cheat. Moreover, alumni may be more willing to speak about academic integrity issues following graduation. Cyclical program reviews are comprehensive and can provide valuable space for academic integrity to be discussed, examined, and improved. The outcomes of a cyclical program review can lead to broader institutional initiatives, develop academic integrity champions across the campus, and inform academic integrity policy enhancements, or changes in process. 


\section{Curriculum Mapping and Educational Development}

Curriculum mapping has become a common component and is often required as part of the cyclical program review in Canadian postsecondary institutions. Curriculum mapping is a collaborative process (Uchiyama \& Radin, 2008) amongst faculty members and an educational developer to ensure curricular alignment. Curricular alignment typically refers to the mapping of course learning outcomes with program learning outcomes (PLO), and with the degree level expectations (DLEs). While mapping styles will differ across disciplines (Rawle et al., 2017), mapping ensures curricular alignment with other program elements such as assessment types, leveling, timing and volume of assessments, and that curriculum is scaffolded to address gaps and redundancies (Dyjur \& Kenny, 2015). Mapping can confirm that the DLE regarding academic integrity is present throughout the curriculum, ensures that students are being taught and assessed on this content and the related research skills that align with their program and discipline across the years of study. In Canada, academic degrees must adhere to the CDQF, and in Ontario, the DLEs found in the OQF. Therefore, if all academic programs were required to include academic integrity as an element in the curriculum mapping session, each program and course would scaffold and support knowledge and skill development regarding academic integrity. Mapping also provides evidence and opportunity to assess if students are being exposed to citation style, writing skills, research best practices and resources for writing. When mapping, educational developers can guide instructors through questions such as: Is there a diversity of assessment types? Has Universal Design for Learning (UDL) been considered? Are certain assessment types more prone to cheating? Are instructors reusing the same assessment year after year? Is there a better way to assess the students? Can a number of smaller, formative assessments take the place of a high-stakes summative exam? CTLs can develop institutional guides which include questions and guide curricular change that support academic integrity. Given that academic integrity is embedded within national degree standards under the section of Professional Capacity/Autonomy (Council of Ministers of Education, 2007, p. 7), it should be evident in program and course learning outcomes to both faculty and students. We also recognize that assessment design is not a neutral endeavor. Faculty, especially part-time or sessional, face long-standing issues in the higher education system (Gagné, 2020) that challenge the ability to make academic integrity forward pedagogical choices (Crossman, 2019). A survey of sessional faculty concluded that some sessional instructors are concerned with a lack of access to teaching and learning resources, and professional development activities (Field \& Jones, 2016). Part-time faculty members could be included in curriculum meetings and quality assurance activities; however, often they are not.

CTLs have the unique opportunity in an academic institution to work with both new teaching staff and experienced faculty. They are typically not considered to be spaces of formal quality assurance; however, they often support program review, curriculum mapping, and curriculum development. They also support a mission for ongoing educational and faculty development. Canadian CTLs are ever evolving in 
their scope of practice and this includes a role with policy and a shift to "quality improvement on a broader scale" (Forgie et al., 2018, p. 5). Canadian college CTLs provide a significant role with "implementing institutional processes that involve both quality assurance and curriculum development" (Liu, 2020, p. 63). CTLs are a rich resource and can integrate academic integrity best practices into faculty development sessions, such as course and assessment design, and positioning good course design as the foundation for academic integrity. Course and assessment design cannot eliminate cheating entirely (Bretag et al., 2019). That said, with what is known about why students cheat and how students learn, there are course and assessment design recommendations to be considered to minimize cheating and support learning (see Carroll, 2013; Christe, 2003).

Educational Developers (note, this role has several other titles (STLHE, n.d.)) can work with faculty and program teams, supporting decision-making regarding assessment design and how assignments that may reduce cheating can be implemented across a variety of disciplines, levels, and modes of delivery. CTLs can also offer professional development opportunities to discuss best practices as well as specific training on how to use text matching software to identify plagiarism and how technology can be used for and against cheating. Educational Developers can provide information to support UDL practices and inclusive assessment design. Inclusive excellence ensures all students have the tools and choices they need for academic success. Several Canadian CTLs also provide academic integrity specialists (e.g., University of Manitoba). Despite campus-wide CTL offerings and expertise, not every support unit, faculty, department, or program is aware of their resources. Therefore, connecting an institutional academic integrity point person with a program undergoing review can be effective, and encourages programs to learn what more they could do to maintain and promote academic integrity.

\section{Engaging with Administration and Governance}

Academic institutions offer governance structures that serve to provide oversight, transparency and a fiduciary duty to university administrative decisions and process (Jones et al., 2001). Governance is a mechanism for shared oversight. Governance bodies play a critical role in the oversight of quality assurance outcomes and upholding campus-wide policy. Governance structures are also a required standard in Canada for degree granting institutions (CMEC, 2007). Members of many Canadian university governance bodies are required to provide oversight and vote upon a variety of academic matters (Pennock et al, 2016). Quality assurance outcomes are typically reported to governance for information or for consideration. For example, educational institutions governance structures usually include a governance oversight body (e.g., Senate or similar delegated committee) whose mandate is to review or approve new program proposals and cyclical program reviews. Similarly, academic misconduct statistics are often reported up to Senate or a similar committee-usually on an annual basis (Neufeld \& Dianda, 2007). Given that both quality assurance and 
academic integrity follow similar governance pathways, there is an opportunity for governance committees to ensure that quality assurance and academic integrity are being adequately addressed, not only from a program level perspective, but from a campus-wide or holistic perspective. At some Colleges, the results of program reviews are presented to Academic Council (e.g., Durham College, 2020, p. 4), to ensure accountability, but also to support the transfer of best practices to institutional stakeholders. The Ontario College system also requires each credential program to establish a Program Advisory Committee (PAC) (MCU, 2009b). PACs could be engaged in a similar way as governance bodies to support academic integrity accountability and initiatives.

Ensuring that members of governance bodies are familiar with the provincial and institutional DLEs, academic integrity policy, and their role to uphold academic integrity standards, raises the level of expectation for program proponents to be academic integrity forward in their program development. Members can also be presented with talks and workshops about quality assurance frameworks and its links to academic integrity (i.e., DLEs), which will raise the level of accountability for proposals moving through governance. Moreover, administration can consider how the annual academic misconduct reporting process can be expanded to include an update on academic integrity educational initiatives across campus. These processes weave both the quality assurance and academic integrity initiatives together and promote continuous educational improvement.

\section{Conclusion}

We have explored how quality assurance processes may not only be an effective tool for managing and assuring program quality, but can also be leveraged to support the continuous improvement of policies and practices, and the development of cultures, in keeping with academic integrity. Connecting quality assurance systems to teaching and learning accountabilities demonstrate that quality assurance and academic integrity are integrally linked-you cannot have one without the other. Colleges and universities are encouraged to explore how they can better integrate their quality assurance and academic integrity practices using examples outlined in cyclical program reviews, curriculum development, educational development, and through work with administration and governance. Highlighting academic integrity in the existing quality assurance processes in Canadian higher education institutions ensures that academic integrity will be considered and built upon from every cyclical program review and focuses on continuous improvement in this area into the future. As Canadian academic institutions continue to build local networks to build cultures of academic integrity, they may also consider advocating for more national support and collaboration to respond to postsecondary issues around academic misconduct, common to all institutions. While the CDQF supports academic integrity, provinces and institutions can weave additional accountability into existing processes and frameworks, to work towards a more holistic approach. 


\section{References}

Academic Integrity Council of Ontario (AICO). (n.d.). Academic integrity council of Ontario. https://academicintegritycouncilofontario.wordpress.com/

Alberta Council on Academic Integrity (ACAI). (2020). Alberta council on academic integrity. https://albertaacademicintegrity.wordpress.com/

Alberta Government. (2018). Alberta credential framework. https://open.alberta.ca/publications/ alberta-credential-framework

Awdry, R. (2020). Assignment outsourcing: Moving beyond contract cheating. Journal of Assessment \& Evaluation in Higher Education, 1-17. https://doi.org/10.1080/02602938.2020.176 5311

Barker, M., \& Pinard, M. (2014). Closing the feedback loop? Iterative feedback between tutor and student in coursework assessments. Journal of Assessment \& Evaluation in Higher Education, 39(8), 899-915. https://doi.org/10.1080/02602938.2013.875985

Bertram Gallant, T. (2008a). Academic integrity in the twenty-first century: A teaching and learning imperative. Jossey-Bass.

Bertram Gallant, T. (2008b). Revisiting the past: The historical context of academic integrity. ASHE Higher Education Report, 33(5), 13-31. https://doi.org/10.1002/aehe.3305

Bretag, T. (2013). Challenges in addressing plagiarism in education. PLoS Medicine, 10(12), 1-4. https://doi.org/10.1371/journal.pmed.1001574

Bretag, T. (2019a). Contract cheating will erode trust in science. Nature, 574, 599. https://www.nat ure.com/articles/d41586-019-03265-1

Bretag, T. (2019b). From 'perplexities of plagiarism' to 'building cultures of integrity': A reflection on fifteen years of academic integrity research, 2003-2018. HERDSA Review of Higher Education, 6, 5-35. http://www.herdsa.org.au/herdsa-review-higher-education-vol-6/5-35

Bretag, T., Harper, R., Burton, M., Ellis, C., Newton, P., van Haeringen, K., Saddiqui, S., \& Rozenberg, P. (2019). Contract cheating and assessment design: Exploring the relationship. Assessment \& Evaluation in Higher Education, 44(5), 676-691. https://doi.org/10.1080/02602938.2018.152 7892

British Columbia, Minister of Advanced Education, Skills and Training (BCMAEST). (2017). Degree program review: Criteria and guidelines. https://www2.gov.bc.ca/assets/gov/education/ post-secondary-education/institution-resources-administration/degree-authorization/degree-pro gram-criteria.pdf

Carroll, J. (2013). A handbook for deterring plagiarism in higher education. Oxford Brookes University Press.

Christensen Hughes, J. M., \& McCabe, D. L. (2006). Academic misconduct within higher education in Canada. Canadian Journal of Higher Education, 36(2), 1-21. https://doi.org/10.47678/cjhe. v36i2.183537

Christe, B. (2003). Designing online courses to discourage dishonesty. Educause Quarterly, 4, 54 58. https://er.educause.edu/articles/2003/1/designing-online-courses-to-discourage-dishonesty

Clarke, R., \& Lancaster, T. (2007). Establishing a systematic six-stage process for detecting contract cheating. InProceedings of the 2nd International Conference on Pervasive Computing and Applications (pp. 342-347). https://doi.org/10.1109/ICPCA.2007.4365466

Council for Higher Education Accreditation, International Quality Group (CHEA). (2015). Corruption in higher education: Can quality assurance make a difference? 5, 1-2. https://www.chea.org/ corruption-higher-education-can-quality-assurance-make-difference

Council for Higher Education Accreditation (CHEA). (2019). Council for higher education accreditation-About. https://www.chea.org/about

Council of Ministers of Education Canada (CMEC). (2007). Ministerial statement on quality assurance of degree education in Canada. http://www.cmec.ca/Publications/Lists/Publications/Attach ments/95/QA-Statement-2007.en.pdf 
Crossman, K. (2019). Is this in my contract? How part-time contract faculty face barriers to reporting academic integrity breaches. Canadian Perspectives on Academic Integrity, 2(1), 1-8. https://jou rnalhosting.ucalgary.ca/index.php/ai/article/view/68934

Curtis, G. J., \& Clare, J. (2017). How prevalent is contract cheating and to what extent are students repeat offenders? Journal of Academic Ethics, 15(2), 115-124. https://doi.org/10.1007/s10805017-9278-x

Dill, D. D., \& Beerkens, M. (2013). Designing the framework conditions for assuring academic standards: Lessons learned about professional, market, and government regulation of academic quality. Higher Education, 65(3), 341-357. https://doi.org/10.1007/s10734-012-9548-x

Durham College. (2020). Policy-Academic Program Review and Renewal-Quality Assurance. https://durhamcollege.ca/wp-content/uploads/academic-program-review-and-renewal-pol icy.pdf

Dyjur, P., \& Kenny, N. (2015, May). Analyzing curriculum mapping data: Enhancing student learning through curriculum redesign. Paper presented at the 2015 University of Calgary Conference on Postsecondary Learning and Teaching, Calgary, AB. https://taylorinstitute.ucalgary.ca/ sites/default/files/resources/handout_CR_5_analyzing_CM_data_2018_01_22.pdf

Engineers Canada. (n.d.). Engineers Canada-About accreditation. https://engineerscanada.ca/acc reditation/about-accreditation

Examity. (2020). Examity-Online proctoring. https://examity.com/

Field, C. C. \& Jones, G. A. (2016). A survey of sessional faculty in Ontario publicly-funded universities. Toronto: Centre for the Study of Canadian and International Higher Education, OISE-University of Toronto. https://www.oise.utoronto.ca/hec/UserFiles/File/Sessional_ Faculty_-_OHCRIF_Final_Report_-_July_2016.pdf

Forgie, S. E., Yonge, O., \& Luth, R. (2018). Centers for teaching and learning across Canada: What's going on? Canadian Journal for the Scholarship of Teaching and Learning, 9(1), 1-18. https:// doi.org/10.5206/cjsotl-rcacea.2018.1.9

Gagné, A. (2020). The Canadian precariat: Part-time faculty and the higher education system. Universitas Press. https://www.ubcpress.ca/the-canadian-precariat

Garwe, E. C. (2019). Quality assurance agencies: Creating a conducive environment for academic integrity. South African Journal of Science, 115(11/12). 47-53. https://doi.org/10.17159/sajs. 2019/6231

Glendinnning, I. (2020). The role of quality assurance and regulatory organizations to promote academic integrity. In T. Bretag (Ed.), A research agenda for academic integrity. Edward Elgar Publishing.

Griffith, J. (2013). Pedagogical over punitive: The academic integrity websites of Ontario Universities. Canadian Journal of Higher Education, 43(1), 1-22. https://files.eric.ed.gov/fulltext/EJ1 007029.pdf

Guerrero-Dib, J. G., Portales, L., \& Heredia-Escorza, Y. (2020). Impact of academic integrity on workplace ethical behaviour. International Journal for Educational Integrity, 16(2), 1-18. https:// doi.org/10.1007/s40979-020-0051-3

Harvey, L. (2008). Placing Canadian quality assurance initiatives in an international context. In Proceedings of CMEC Quality Assurance Symposium 2008, (pp. 2728). https://www.univcan.ca/wp-content/uploads/2015/07/qa-placing-canadian-qa-initiatives-ininternational-context-2008.pdf

Indigenous Knowledge Gifters' Council (IKGC). (2018). Building a strong fire: Indigenous quality assurance standards in Ontario colleges. http://www.northernc.on.ca/indigenous/pdf/BuildingA StrongFire_WEB.pdf

International Centre for Academic Integrity (ICAI). (2020). ICAI-About. https://www.academici ntegrity.org/about/

International Network for Quality Assurance Agencies in Higher Education (INQAAHE). (2020). INQAAHE-Membership. https://www.inqaahe.org/membership 
Jacobsen, D. M., Eaton, S. E., Brown, B., Simmons, M., \& McDermott, M. (2018). Action research for graduate program improvements: A response to curriculum mapping and review. Canadian Journal of Higher Education, 48(1), 82-98. https://doi.org/10.47678/cjhe.v48i1.188048

Jones, G., Shanahan, T., \& Goyan, P. (2001). University governance in Canadian higher education. Tertiary Education and Management, 7(2), 135-148. https://doi.org/10.1080/13583883.2001. 9967047

Liu, Q. (2020). The impact of quality assurance policies on curriculum development in Ontario postsecondary education. Canadian Journal of Higher Education, 50(1), 53-67. https://doi.org/ 10.47678/cjhe.v50i1.188301

Macdonald, R., \& Carroll, J. (2006). Plagiarism - A complex issue requiring a holistic institutional approach. Journal of Assessment \& Evaluation in Higher Education, 31(2), 233-245. https://doi. org/10.1080/02602930500262536

Manitoba Academic Integrity Network. (2019, MAIN). About-Manitoba academic integrity network. https://mbacademicintegrit.wixsite.com/main

Maracle, Bonnie Jane/Iehnhotonkwas. (2020). Seven grandfathers in academic integrity, University of Toronto, First Nations House. https://studentlife.utoronto.ca/wp-content/uploads/SLC8581_7Grandfathers-in-Academic-Integrity-AODA.pdf

Maritime Provinces Higher Education Commission (MPHEC). (n.d.). Maritime degree level qualifications framework. http://www.mphec.ca/resources/DegreeLevelFrameworkEn.pdf

McKenzie, A. (2018). Academic integrity across the Canadian landscape. Canadian Perspectives on Academic Integrity, 1(2), 1-6. https://doi.org/10.11575/cpai.v1i2.54599

McKenzie, A. (2019). Enhancing academic integrity through quality assurance. Canadian Symposium on Academic Integrity. https://prism.ucalgary.ca/handle/1880/110296

McKenzie, A., Miron, J., \& Ridgley, A. (2020). Building a regional academic integrity network: Profiling the growth and action of the academic integrity council of Ontario. Canadian Perspectives on Academic Integrity, 3(1), 25-38. https://doi.org/10.11575/cpai.v3i1.69836

MCU, Ministry of Colleges and Universities. (2018). Ontario qualifications framework (OQF). http://www.tcu.gov.on.ca/pepg/programs/oqf/

MCU, Ministry of College and Universities (MCU). (2009a). Essential employability skills. http:// www.tcu.gov.on.ca/pepg/audiences/colleges/progstan/essential.html

MCU, Ministry of Colleges and Universities (MCU). (2009b). Minister's binding policy directiveFramework for programs of instruction. http://www.tcu.gov.on.ca/pepg/documents/Framework forPrograms.pdf

Morris E. J., \& Carroll J. (2015). Developing a sustainable holistic institutional approach: Dealing with realities 'on the ground' when implementing an academic integrity policy. In T. Bretag (Ed.), Handbook of academic integrity. Springer.

New Zealand Quality Assurance (NZQA). (n.d.). Quality assurance division. https://www.nzqa. govt.nz/about-us/our-structure/quality-assurance-division/

Neufeld, J. \& Dianda, J. (2007). Academic dishonesty: A survey of policies and procedures at Ontario universities. https://cou.ca/wp-content/uploads/2015/07/Academic-Colleagues-Aca demic\%20Dishonesty-A-Survey-of-Policies-and-Procedures-at-Ontario-Universities.pdf

Northern College. (2017). Quality assurance policy. http://www.mynorthern.ca/wp-content/upl oads/2018/08/VPA-1-Quality-Assurance-QA-Policy1.pdf

Ontario College Quality Assurance Service. (2016). Stages of the audit process. https://www. ocqas.org/wp-content/uploads/2015/08/CQAAP-Stages-of-the-Audit-Process-Revised-Feb-102016.pdf

Ontario College Quality Assurance Service. (2020). About college quality assurance audit process (CQAAP). https://www.ocqas.org/quality-assurance/about-cqaap/

Ontario Universities Council on Quality Assurance (OUCQA). (n.d). OCAV's undergraduate and graduate degree level expectations. https://oucqa.ca/wp-content/uploads/2013/06/APPENDIX1.pdf 
Penaluna, L., \& Ross, R. (2022). How to talk about academic integrity so students will listen: Engaging students in ethical decision making. In S. E. Eaton \& J. Christensen Hughes (Eds.), Academic Integrity in Canada. Springer.

Pennock, L., Jones, G. A., Leclerc, J. M., \& Sharon, X. L. (2016). Challenges and opportunities for collegial governance at Canadian universities: Reflections on a survey of academic senates. Canadian Journal of Higher Education, 46(3), 73-89.

Poitras Pratt, Y., \& Gladue, K. (2022). Re-defining academic integrity: Embracing indigenous truths. In S. E. Eaton \& J. Christensen Hughes (Eds.), Academic Integrity in Canada. Springer.

Quality Assurance Association for Higher Education (QAA). (2017). Contracting to cheat in higher education: How to address contract cheating - the use of third-party services and essay mills. https://www.qaa.ac.uk/docs/qaa/quality-code/contracting-to-cheat-in-higher-education.pdf

Quality Assurance Association for Higher Education (QAA). (2020). Contracting to cheat in higher education: How to address essay mills and contract cheating-2nd Edition. https://www.qaa.ac. uk/docs/qaa/guidance/contracting-to-cheat-in-higher-education-2nd-edition.pdf

Quality Assurance Association for Higher Education (QAA). (n.d.). QAA-Academic integrity. https://www.qaa.ac.uk/about-us/what-we-do/academic-integrity

Robson, K. (2012). Sociology of Education in Canada. Pearson Canada.

Rawle, F., Bowen, T., Murck, B., \& Hong, R. (2017). Curriculum mapping across the disciplines: Differences, approaches, and strategies. Celt-Collected Essays on Learning and Teaching, STLHE. https://doi.org/10.22329/celt.v10i0.4765

Society for Teaching and Learning in Higher Education (STLHE). (n.d.). Educational developers caucus-job descriptions. https://www.stlhe.ca/affiliated-groups/educational-developerscaucus/resources/job-descriptions/

Stoesz, B., Seeland, J., Vogt, L., \& Markovics, L. (2020). Creating a collaborative network to promote cultures of academic integrity in Manitoba's post-secondary institutions. Canadian Perspectives on Academic Integrity, 3(1). 1-10. https://journalhosting.ucalgary.ca/index.php/ai/ article/view/69763

Stoesz, B. M., Eaton, S. E., Miron, J., \& Thacker, E. J. (2019). Academic integrity and contract cheating policy analysis of colleges in Ontario, Canada. International Journal for Educational Integrity,15(4), 1-18. https://doi.org/10.1007/s40979-019-0042-4

Sutherland-Smith, W. (2014). Legality, quality assurance and learning: Competing discourses of plagiarism management in higher education. Journal of Higher Education Policy and Management, 36(1), 29-42. https://doi.org/10.1080/1360080X.2013.844666

Temponi, C. (2005). Continuous improvement framework: Implications for academia. Quality Assurance in Education., 13(1), 17-36. https://doi.org/10.1108/09684880510578632

Tertiary Education Quality and Standards Agency (TEQSA). (2020). TEQSA—What we do. https:// www.teqsa.gov.au/what-we-do

Tertiary Education Quality and Standards Agency (TEQSA). (2020, June 24). TEQSA to establish new higher education integrity unit. https://www.teqsa.gov.au/latest-news/articles/teqsa-establ ish-new-higher-education-integrity-unit

Truth and Reconciliation Commission of Canada (TRC). (2015). Truth and reconciliation commission of Canada: Calls to action. http://nctr.ca/assets/reports/Calls_to_Action_English2. pdf

Turnitin. (2020). Turnitin for higher education. https://www.turnitin.com/divisions/higher-edu cation

Uchiyama, K. P., \& Radin, J. L. (2008). Curriculum mapping in higher education: A vehicle for collaboration. Journal for Innovative Higher Education, 33, 271-280. https://doi.org/10.1007/ s10755-008-9078-8.pdf

UNESCO. (2007). Quality assurance and accreditation: A glossary of basic terms and definitions. http://proiecte.aracis.ro/fileadmin/ARACIS/Publicatii_Aracis/Publicatii_ARACIS/Eng leza/Glossary_07_05_2007.pdf

United States Department of Education. (n.d.). Federal role in education. https://www2.ed.gov/ about/overview/fed/role.html 
Universities Canada. (n.d.). Universities Canada-membership criteria. https://www.univcan.ca/ about-us/membership-and-governance/membership-criteria/

Weinrib, J., \& Jones, G. A. (2014). Largely a matter of degrees: Quality assurance and Canadian universities. Policy and Society, 33(3), 225-236. https://doi.org/10.1016/j.polsoc.2014.07.002

Emma Thacker M.A. is an administrator at the University of Toronto, specializing in governance, policy and ombuds work. She has held several positions to support institutional quality assurance, academic integrity and quasi-judicial affairs. Emma is a doctoral candidate in the School of Social, Political and Global Studies at Keele University, United Kingdom. Her doctoral research focuses on academic literacies and contract cheating. Emma is an active member of the Association of Canadian College and University Ombudspersons (ACCUO) and the Academic Integrity Council of Ontario (AICO). She has research interests in higher education policy and academic integrity education.

Amanda McKenzie M.A. is the Director of Quality Assurance (Academic Programs) and oversees quality assurance and academic integrity at the University of Waterloo. She is involved in academic integrity initiatives on a provincial, national and international level. Amanda is an active subject matter expert in this area and has spoken around the world. She has also published a number of articles and a book chapter in this field. Amanda has served as part of the International Center for Academic Integrity since 2016 and has been an Officer on the Board of Directors since 2018. She is also an active member of the Academic Integrity Council of Ontario (AICO) and currently serves as the Secretary/outreach Coordinator.

Open Access This chapter is licensed under the terms of the Creative Commons Attribution 4.0 International License (http://creativecommons.org/licenses/by/4.0/), which permits use, sharing, adaptation, distribution and reproduction in any medium or format, as long as you give appropriate credit to the original author(s) and the source, provide a link to the Creative Commons license and indicate if changes were made.

The images or other third party material in this chapter are included in the chapter's Creative Commons license, unless indicated otherwise in a credit line to the material. If material is not included in the chapter's Creative Commons license and your intended use is not permitted by statutory regulation or exceeds the permitted use, you will need to obtain permission directly from the copyright holder.

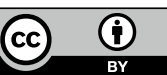

